\title{
Among territorial project and architectural design
}

\author{
Michele Valentino ${ }^{1 *}$ and Laura Lutzoni ${ }^{2}$
}

\begin{abstract}
The contribution develops a reflection on the urban space project in contexts characterized by historical-cultural relevance by exploring interdisciplinary approaches through the intersection of research and didactic actions in the field, which make the project emerge from specific ways of interacting with local societies. These relationships find a sense starting from the identification of some traditionally configured places in the city that present obsolete functions or abandoned conditions, but characterized by a strong urban value and can become hubs of potential and learning laboratories. In this sense, knowledge can be a tool capable of favouring forms of social relations and initiating the construction of new citizenships.

The research identifies in the context of the historic city of Sassari some nuclei of urbanity, spaces and significant areas of the city that more than others recall an educational dimension. The relationship between the formative character of the historic city and the emergence of new forms of sociality favours the possibility of identifying areas outside standardization that contain the genetic code of urban conviviality. In this perspective, public space defined as the place of production of sociality, designed to bring out a different urban organization.

The identification of these latent traces of a system full of meaning and full of potential for urban life can open fertile perspectives to think of new spaces of relationship for active participation in the project of the city. Marking the distance from an object-oriented position in favor of an ontology of urban and territorial relations, the project continuously aimed at revealing new forms of spatial distribution that relate different nuclei, interpreting their specific role in the overall system of generative structures environmental aspects of the city.
\end{abstract}

Keywords: Urban territories, Educational environment, Urban planning, Urban nuclei, Urban regeneration

\section{Define urban territories}

Trying to define what the city is today, not one in particular but the city in a broader sense, is a complex action. The significant transformations that have affected urban territories, also concerning the spatial dimension, undermine the methods of construction and articulation of urban complexity. This condition requires a rethinking of urban form and structure, which presents itself differently than the idea and the images that modernity has given us.

\footnotetext{
*Correspondence: mvalentino@uniss.it

${ }^{1}$ Dipartimento Di Architettura, Design E Urbanistica, Università Degli

Studi Di Sassari, Alghero, Italy

Full list of author information is available at the end of the article
}

As stated by Jean Gottmann (2005), the city and the territory are entities in "evolution", an evolution that has been constant throughout history. This is evidenced by what we today mean by city and territory, entities that are difficult to describe and separate.

The condition of the contemporary city opens up reflections, highlighting the differences with the modern city and a profound diversity with the relative culture that produced it. The distinctive features that structure the city induce urban planning and architecture to establish a constant comparison with new themes, different from those that characterized the period of recent urban expansion.

In the disciplinary debates of architecture and urban planning the themes that mostly involve the city assume a 
specific relevance starting from the end of the sixties, but they find only in the last two decades of the last century the period of maximum diffusion, in net delay compared to the reflections introduced by other disciplines. ${ }^{1}$ The controversial debate that develops around post-modernity, starting from the main characters of architectural language, begins to take on a broader, organic and widespread dimension, projecting itself towards the so-called "urban question" (Marcelloni 2005).

The extended condition of the city-territory seems to be one of its clearest connotations as the physical urban dimension invades territories. As Massimo Cacciari maintains, the city is everywhere, and we no longer live in cities but in territories (Cacciari 2004) whose borders configured as pure artifice. The difficulty lies in avoiding that the proliferation of boundaries without limits remains only a play on words (Lo Piccolo 2017).

The urban system develops in every place, starting from the cities it has spread in the countryside and makes no distinction in the various urban realities. The relationship between city and territory, changed in history, defines the contemporary space of urban life. As Giovanni Maciocco states, today it is difficult to define what the city is perhaps because we are no longer able to see it in its entirety, as it emerged from the walls it became a territory and transformed the inhabitants into territorial men (Maciocco et al. 2011a, b).

The understanding of the contemporary city is, first of all, invalidated by a collective imaginary that describes it. The current heterogeneity of situations, the multiplicity of languages makes us understand the complexity of the city of the past. In the essay, The Land as Palimpsest, André Corboz (1985) uses the literary metaphor of the schedule to describe the long stratification path to which cities and territories subjected, the result of different rewriting processes. In this sense, the city should be explored as a complex text, a text in which buildings, urban fabrics and territorial dimensions must interpret inseparably.

The dimensions and forms that the contemporary city shows us bring into play new questions that have unprecedented relationships concerning the traditional city, overturning phenomena and rendering cultural instruments obsolete, including its representation and representability. Most of readings and images of the contemporary city characterized by the persistence of the

\footnotetext{
${ }^{1}$ See the reflections proposed in the volume "The postmodern condition" (Lyotard 2008) on the end of the meta-narratives of modernity, capable of providing a linear and certain legitimacy to the way of thinking and acting in terms of progress. The appearance of an uncertain society illustrated in the courses held at the Collège de France since 1970, in particular, the course of 1977-78, Sécurité, territoire, population, and taken up in Foucault's writing (2007).
}

term city even if the new nomenclatures document how the territorial dimension has become indispensable in the context of an enlarged city. In this sense, each design gesture must take into account not only settlement of compact city or subsequent settlement "frays", but above all their relationship with the morphology of the territory and the environment. Some researches, ${ }^{2}$ changing the point of view on the phenomena, propose to put at the center of the reasoning the term territory. It is allowed, by rejecting similarities with the historic city, a different interpretation of the settlement conditions that characterize it. With these premises, we could consider the contemporary city as an urban territory, ${ }^{3}$ wherein the term territory the physical and spatial dimension is recognized and in the urban term that linked to different forms of settlement and life.

The sudden change of the urban dimension started in the Sixties and up to the present day, has imposed a modification of the project disciplines with the consequent crisis in their formalized languages and related tools. Once the continuous pressure has disappeared from the modern movement, urban planning has only started to set rules, minimizing the cognitive phases of the design process and the cognitive-selective phases of the design. With the plans of the sixties and seventies, the table of the plan is transformed into a map of norms (Gabellini 1996) ${ }^{4}$ recording the deterioration of the technical criteria regulated in the urban planning law of $1942 . .^{5}$ The urban design becomes a map where the traces of the history and geography of the territory are increasingly laboriously identified. During the seventies, the gradual cultural change of urban planning began, with the related languages and tools, based on a progressive reflection on the shape of the plan and the project of the city. In these years, while developing new tools (detailed plans for historical centres, plans for productive settlements, etc.), the plans are still characterized as expansion plans, but at the same time, the first attempts to optimize urban growth appear. A propensity appears towards a new urban design based on the specificity of the city where the first attempts

\footnotetext{
${ }^{2}$ Reference is made to the "territories of dispersion" by Bernardo Secchi where the analogy with the city is avoided, describing an urban phenomenon different from the settlement condition of historical or modern cities. Even in the research of Fernando Clemente (1974) and later of Giovanni Maciocco (Maciocco et al. 2011a, b), we wonder about what the emerging forms of the contemporary city are and what meaning the territory can take on in urban life.

${ }^{3}$ For further details, look at Michele Valentino's doctoral thesis: "The urban territories project. The environmental dimension in the city project.".

${ }^{4}$ In Il disegno urbanistico Gabellini (1996) he observes this slow decline, where the norms take on increasing importance on the project design.

5 The national urban planning law 1150/1942 introduces the instrument of the Piano Regolatore Generale (PRG).
} 
at integration between the new city and the historic city appear. In Italy, only in the eighties and nineties does a new family emerge of the plan and therefore of representations of the city and the territory where the first morpho-typological readings of the city produced, capable of tracing and identifying the material dimension of space, and where they begin to produced iconic tables made of mending and rebuilding of the existing determined through the design of the open space. Bernardo Secchi (1986) in the article Progetto di Suolo states the need for more considerable attention to the urban project where each part of the city strongly recognized by the articulation of the different collective and private spaces. Is precisely through continuous steps of scale that it is possible to put in light the different levels of the spatial articulation that characterize the city-territory (Secchi 1986). At the same time, an ever-higher sensitivity to the environmental dimension emerges, provoked by the trespassing of the urban reality that has changed profoundly with its territorial dimension that imposes the need for profound changes in the design of urban planning instruments. This new awareness turns into more considerable attention to the problems of spatial organization that refers to the limits concretely placed by the natural environment to urban development, making the environmental resources an opportunity to restore structure to anthropic development (Maciocco 1991).

In the following years a new season and a new family of plans began, the Structural Plans, ${ }^{6}$ such as the Structure Plan of Anversa by Bernardo Secchi and Paola Viganò, which set the goal of exploring an unprecedented process capable of dealing with new instruments cognitive and original design methods, the paradigmatic questions of the modifications underway in the contemporary European city. Other experiences, such as the Tiber strategic area of the Rome PRG 2000 or the Epicentres identified in the Milan PGT (Territorial Government Plan) of 2004, define scenarios concerning the policies or priorities of the territory. At the same time, we are witnessing a gradual return to the urban and territorial project, which, starting from a departure from prescriptive planning, sees in the regulative excess an inadequate and ineffective apparatus for the city project. Furthermore, a practice launched aimed at particular projects and often self-referential architectural gestures. ${ }^{7}$

\footnotetext{
${ }^{6}$ The elaborations of the seven images of cities that deal with physical space and practices (Waterstad, Spoorstad, Havenstad, Megastad, Villages and Metropolis, Ecostad and Poreuzesta) appear attractive, able to describe the same urban and territorial reality in different ways.

7 The "Guggenheim effect" of Bilbao (Jenks 2005), started a substantial urban regeneration action, made of iconic landmark building, from the late nineties. This phenomenon has assumed relevance in the following years all over the world with the phenomenon of the archistars and the great internationally renowned architects.
}

The contemporary city, on the other hand, with its evolving character, should push designers towards a design experimentation-exploration that needs more current and flexible systems than those conceived for the modern city, finding the reasons for the project in the relational context of the emerging elements and in the innovative questions to be investigated (Castells 1977; Secchi 2010; Merrifield 2014).

The mechanism that supported the relationship between city and territory typical of the modern period in a pyramidal system is interrupted, and new ways of living in the contemporary city manifested. More and more often, we find ourselves in the presence of a fragmented and isotropic space, where the hierarchies of the modern are broken up by new social and productive organizations. The focus on a collective idea that represents the city as a unitary system of built-up areas now heads towards environmental spaces, considered in the past the city's counter-spaces (de Solà-Morales 1995). Overcoming the debate on the forms of urban settlement (Sernini 2000) involves the assimilation of the territory to the city. The urban territories project, assuming the territory as the cornerstone of urban life, takes on the dimension of the landscape and the environment as an opportunity for the urban quality project, overcoming the dichotomous comparison between nature and artifice, unworkable in the contemporary city.

Many design experiences, make environment interact with settlements, confronted with a new disciplinary configuration capable of experimenting with the role of the environment in the project of the city and the territory. The environment, no longer seen as other than the city or as a filler of spaces between buildings, becomes a central element for establishing unprecedented relationships in urban territories. Relationships capable of enriching the physical centrality of urban life by giving the "spatial structures and dense concepts of nature and history" (Maciocco and Tagliagambe 1997, p. 200). The task of generative structures (Maciocco et al. 2018) in the project of urban territories. Revealing the possibilities of these places, intended through the planning intention of the territories-structure (Maciocco et al. 2011a, b), gives a structural role to the territory, reversing the relationship between figure and background (Tagliagambe 2005) between city and environment. In this regard, in perspective of enlarged city and with emergence of new environmental sensitivity, the urban territory is centred around the density of nature and history. The territories take shape contradicting the need to live without space. They are organized as territories-structures that reveal environmental dominants as generators of a different order of settlement space (Maciocco et al. 2011a, b). In the territory, unlike the modern city, the contemporary city and 
nature meet, giving the possibility to the project to reorient them around the environmental dominants, expressing all the "urban potential of the territory".

If one uses the metaphor of the organism to describe the city, it can be represented as a hierarchical relationship between its parts, configuring itself as an ordered series of degrees and situations. In this sense, the city can consider as a whole ordered by different parts to which it is possible to give form to assign functions and roles to which they are called to perform (Secchi 2000). In this organisation, the people who live in the places are involved as a relationship of dependence is created between them, expression of different social conditions. The hierarchy concept is easily associated with the periphery, which presupposes a comparison between centrality and marginality and implies the definition of a system in which different parts are formed and developed. In the contemporary city, this hierarchization between the parts does not necessarily include a corresponding geometric organisation: the centre and the periphery can be configured according to different spatiality, subverting their traditional spatial localisation. In this sense, the binary scheme of centre-periphery relationship deconstructed in its rigidity in favour of new points of view and perspectives.

Although the main dynamics that characterise the cityterritory are increasingly explicit and describable, some reflections linked to the design perspective remain open. The difficulty of identifying a unitary and overall project capable of reflecting the changed characteristics of the urban condition that expands towards the territory becomes a relevant aspect and determines disciplinary disorientation.

Despite the recognition of the territorial dimension as an essential feature of the contemporary city, many studies focus on the study of the dynamics that characterise the city with a high density of settlement, recalling indications and design approaches typical of the modern city. However, as Francesco Indovina states, numerous studies have described new urban landscapes, between the 'countryside' and 'metropolis' different levels of occupation of the territory have identified, different levels of modification of the countryside, in a scale that cannot be hypothesised to be always travelled and whole (Indovina 2005). Density does not, therefore, appear to be a discriminating factor for the recognition of the city: the urban is a condition of contemporary living that is articulated and manifested throughout the entire territory.

\section{City as learning environment}

The overcoming of boundaries in the compact city and the irruption of the environmental dimension in the urban horizon has favoured an 'extended use' of the territory. An 'expansion of the concept of living', which has a spatial and functional sense, since it incorporates all the functions - of residing, of producing, of exchanging-through which man lives in a pleasantly complex way, and which corresponds, in Heidegger's sense, to 'taking care' of the entire territory, to become aware of values, to judge the sense of every transformation of reality (Maciocco and Tagliagambe 1997). All this translates into settlement forms that cannot be circumscribed to a definite and specific perimeter and implies a series of changes that go to invest the territory, posing new problems and new orders of relationships. The environmental dimension has produced significant changes in the minds of people and their imagination, causing profound transformations in social demand.

This process, accompanied by a phenomenon in which every reference and every link between individual choices and collective projects or actions is missing (Bauman 2011). From this derives a solitude of the individual (Bauman 2014), which becomes the holder of the freedom of action and experimentation, from which however it also follows the need to face the consequences of one's action in a completely distinctive way. In reality, nobody, no matter how cosmopolitan and virtually interconnected with the world, can do without urban places (Mela 2018). It is around the places that can trace back to a broader territorial dimension that human experience tends to form and articulate, this is where the attempt to manage the shared dimensions of life conducted, it is here that the meanings of existence outlined, absorbed and negotiations (Bauman 2008).

The expansion of the concept of living has generated significant repercussions also on educational processes as referring to the territory, and not only to the city, has led to an expansion of the concept of education, abandoning the perspective according to which the school and its space inside they can become more educational if designed as an urban microcosm that incorporates the spatial codes of the city (De Carlo 1947). This evolution can be summarized through some significant passages briefly illustrated below.

In 1938 Mumford in the book, The culture of the Cities outlines the evolution of the relationship between school and city and identifies in the latter value as a community nucleus (Mumford 1999). Mumford introduces the theme of spatial concentration by placing the school as a pivot of future spatial organization and giving it great importance concerning social relations. According to the author, education can understood as an extension, refinement and integration of human experience in its various aspects (Mumford 1999). In this context, school is part of spatial entities of both existing city, as one of the fundamental representations of the nineteenth and 
twentieth-century welfare, but also becomes the cornerstone in the expansion of the city. All this opens up the possibility that the school may represent the center of a city no longer confined to the walls. In this perspective, urbanity begins to be attributable not only to a central place but becomes a field phenomenon.

A decade later, Ernesto N. Rogers (1947) in a Domus editorial entitled Architettura Educatrice, explores the topic of the school. In this short text emerges first and foremost how space is the stable version of moral principles and this appears even more relevant if we consider the school as a matrix of the rights of the individual and from which all his duties are achieved (Rogers 1947). Rogers links the spatial component to education, what happens in the order of values, ways of thinking, which are not something given, but what makes an individual unique through the enhancement of human potential. The architect maintains that the problems of education cannot be solved by referring to other areas since pedagogy cannot replace the architectural dimension.

In the contribution, La scuola e l'urbanistica included in the same issue of the magazine, De Carlo (1947) argues that the urban school problem has become the urban problem of the city. The author $(1972,1973)$ also introduces the possibility that school buildings and their interior space may assume a more educational character by recalling the spatial codes of the city.

Somehow both Rogers and De Carlo consider education as a problem not only related to the internal space of schools, paving the way to a reticular dimension of the educational phenomenon. In particular, De Carlo develops (1972) the idea of a unicum between school and society by promoting an education that is the result of global experiences and that integrates the school and the urban context since the knowledge of the city is educational material.

The complicated relationship between school and city delineated by De Carlo is deepened at the end of the sixties by Michelucci (2010) through the idea that the school is the city. There is, therefore, no need to simulate the characteristics of urban functionalism in schools, but the city itself is a place of learning. The idea of the city is a space of knowledge and innovation, in which one learns by walking in urban places, as in an open-air school. The outdoor school requires a collaborative structure and the possibility of constant contacts and exchanges. Reversing perspective, the role of architecture in the definition of the city would also modified with a consequent emphasis on its task as a tool for understanding society.

The idea of starting from the school-city link to reinterpret it in the current social complexity allows to operate in both realities and projects towards a broader scenario in which the territory defined tota field of urban manifestations that identify it and whose problems, therefore, they cannot approach without explicit reference to the urban context that expresses them (Clemente 1974). In this perspective, the reflection on the educational city to the landscape-environment extended: the territory becomes educational in its complicated and therefore generates training experiences.

The prospect that considering the city and the territory in their complexes as environments define "plots of learning" (Illich 1972; Lutzoni 2017). Urban networks increasingly intertwined and usable within an extended system and spatially articulated, it makes it possible to identify the territory as a privileged place in which culture is transmitted, through a perspective that considers the city-territory, in its many forms and dimensions, as a relational place (Maciocco et al. 2011a, b). Within the volume, Deschooling Society Illich (1972), departing from the common idea that education is synonymous with equality between individuals, proposes some reflections on the relationship between school and the urban environment. According to the author, the current school model confers success/failure on individuals in the achievement of particular social roles, assigning them the responsibility for this process which, according to the author, would depend on numerous independent economic, social and cultural factors compared to the individual's abilities. Education goal instead to accompany the individual in growth by developing the ability to learn and relate to the context. From emerges need to free education from the "school", understood both as a physical space and an institution. In this sense, Illich proposes a structured educational model through a collaborative process without hierarchies and pre-established roles, in which educational activities spatially distributed throughout the territory. In this perspective, learning means acquiring autonomously new knowledge and ability to build relationships.

As part of the debate related to the possibility of identifying external education to traditional models, Colin Ward also made an essential contribution through reflections on the design of learning environments outside the school, exploring, in particular, how children make creative use of the urban environment (Ward 2000). The latter represent subjects in action who are entitled to adequate times and places through the spontaneous use of urban spaces. The relationship between school and city is investigated by the author in the contribution Schools no longer (Ward 1973) which frames the question of school education with particular reference to the writings of Illich (1972) and Reimer (1973) and to the reflections of the anarchist educator Goodman (1964), focusing on learning practices and spaces located outside the school building. In the book Streetwork: the exploding school, 
Ward and Fyson (1973) consider the urban environment as a useful resource for children and emphasize the possibility of educating the new generations on the use of the city in high places potential to develop new life experiences. In this perspective, we talk about the need to ensure that the school "explodes" in the urban environment with progressive growth of informal structures. In this sense, education can take place from an intelligent observation of the environment and is structured starting from the contact with the community and with its problems as the young people must complete the scholastic path not only by understanding reality but also by having developed the aptitude to act in it as aware citizens. This fieldwork can build a bridge between school and real-life through constant involvement in local problems (Ward and Fyson 1973).

In the same direction, the volume City as Classroom: Understanding Language $\mathcal{E}$ Media of Marshall Mc Luhan et al. (1980) proposes a series of exercises and activities of perception and awareness of the school and urban environment. These activities, which start with the search for relations outside the classroom, consider the city a formative space in which the environment in constant transformation is the background, while the observer represents the figure: the interaction between observer and environment, figure and background, generates a change in the same observer. It is an opening where one enters into a relationship with the city and assumes the spatial awareness of apprehension in urban space. In this perspective, the city constitutes an instrument of self-evident didactics (Brusa 2012) and the development of learning processes in the city and the territory can assume an enormous potential in social, environmental and economic terms, encouraging innovation and the development of knowledge economies and including within it informal dynamics and processes. The tendency in favour of urban learning plots characterized by a multiplicity of situations and conditions also emerges within some recent research which, linking to the reflections previously illustrated, propose a model in favour of a broad educational perspective (Campagnoli 2007, 2015; Gallo and Mottana 2017; Mottana and Campagnoli 2016). According to this view, the school should bind itself to everyday life (Lefebvre 1977) and at the same time, open up to a broader vision through a progressive expansion of educational activities in the territory. In the volume, The educating city, Mottana and Campagnoli (2016) propose a radical alternative to the current scholastic institution experiencing a condition in which urban spaces become places of learning and school buildings represent only one of the elements of a more articulated and diffused network in the territory (Gallo and Mottana 2017).
Overcoming the processes of closure and spatial concentration of the places pre-posed to education prefigures an urban dimension in which urbs and civitas establish a bond of reciprocity that finds its strength in the territorial dimension. In this sense, if we consider architecture as a sign imparted by a man in places (Rossi 1966), the city and the territory become areas of sharing and exchange that change through a continuous dialogue with the context (Maciocco and Tagliagambe 2009). In this sense, the educational space is urban space and education is not linked solely to school buildings, but a process characterized by a broader perspective (Serreli and Calidoni 2017).

Starting from these reflections, it is, therefore, possible to start some considerations related to the relational dimension of the educational phenomenon for the city-territory. The overcoming of the boundaries of the compact city and the irruption of the environmental dimension has favoured a "wide use" of the territory, an "expansion of the concept of living" (Maciocco and Tagliagambe 1997, p. 125). The definition of settlement forms that cannot circumscribe to a definite and specific perimeter implies a series of changes that go to invest the territory, posing new problems and new orders of relationships. The environmental dimension has produced significant changes in the minds of people and their imagination, causing profound transformations in social demand. This process, accompanied by a phenomenon in which every reference and every link between individual choices and projects or collective actions is missing (Bauman 2011). From this derives a solitude of the individual (Bauman 2014), which becomes the owner of freedom of action and experimentation, from which however also the need to face the consequences of one's action derives in a completely distinctive way. In reality, no one, no matter how cosmopolitan and virtually interconnected with the world, can do without urban places (Mela 2018) that refer to a broader territorial dimension.

In this perspective, expansion of living concept had significant repercussions also on educational processes as referring to the territory, and not just to the city, has led to an expansion of the concept of education. The city-territory is considered as a resultant landscape, not of a process of collective interpretation, but tied to the individual experience of living. The city-territory enters a process of liquefaction (Bauman 2011) and the traditional models with which the project of educational spaces faced need a further advancement concerning the second prospect which the city and the territory represent a formative space. In this sense it is possible to start from education to encourage the emergence of new forms and ways of living, to relate urbs and civitas. The city is no longer merely a learning space, but education itself can offer 


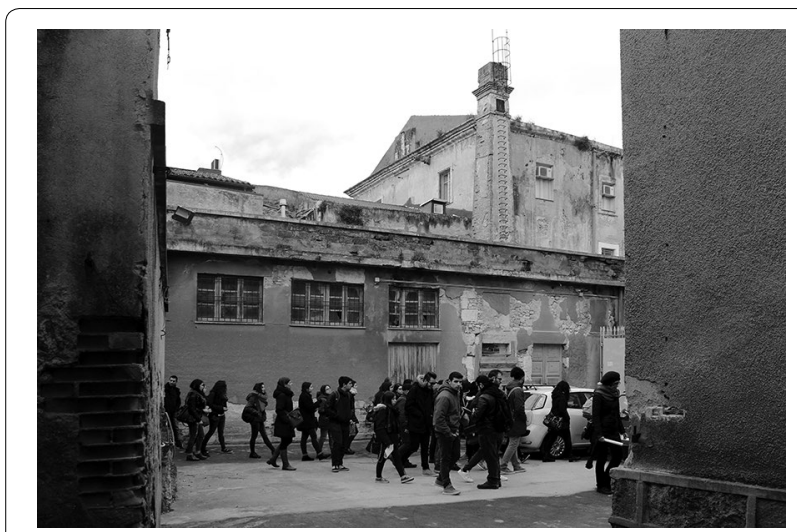

Fig. 1 Site visit to the project areas. Internal space of the former Jesuit College, headquarters of the University of Sassari, Sassari. Photo: R. Filippelli

interesting perspectives in terms of urban regeneration processes (Ostanel 2017).

\section{Urban regeneration and educational perspectives for urban territories}

The theme of urban regeneration is presented as a complex topic as it addresses spatial, social, economic and environmental issues. Within this perspective, the project laboratory Idee per una città accogliente, at Department of Architecture, Design and Urban Planning (DADU) of the University of Sassari, explored the theme of urban regeneration in the context of the historic city of Sassari. A central area but at the same time peripheral and marginal of the city, which is characterized by a fragmented spatial context, conditions of intense social unease and by the significant presence of foreign inhabitants who come from different cultures, but also for a dynamic network of social relations. The historical city has peripheral features, an inversion of the relationships between things, that is to say, an inversion of the usual order between the terms centre and periphery where a centre has become periphery (Fig. 1). ${ }^{8}$

The laboratory has started a reflection on the theme of the welcoming city concerning the space project, with the awareness that the project of physical space is not enough to improve society. In this sense, the research was

\footnotetext{
${ }^{8}$ Public services have progressively moved towards the artisan-commercial area of Predda Niedda and the residences towards the "appendages" of the city built at the beginning of the last century. Furthermore, immigration has changed the characteristics of the urban fabric, not only in the demographic composition and in the ethnic groups present, but above all in the different way of living the public space and in the ways of considering the city and its spatial form. In this reference scenario, the town becomes the context in which concepts such as inclusion translate into apparent forms of conflict and estrangement.
}

directed towards the goal of revealing the city as a place favorable to welcoming and open to dialogue in which it is possible to build a formative environment (Clemente 1969, 1974; Serreli and Calidoni 2017; Lutzoni 2017) capable of to encourage meeting and develop different forms of social relations.

This scenario has made it essential to create moments of exchange and deepening, as well as participatory paths, capable of establishing a reciprocal exchange between the different subjects that inhabit this territory in favour of a project capable of generating a sense of belonging to the city. To implement these, it was put in place an ongoing dialogue process with the inhabitants, even from other places and cultures, with the institutions, committees and the cultural associations operating in the territory. ${ }^{9}$ In particular, the moments of debate and the seminars, structured in an open and participatory form, were taken as directed to initiate reflections and promote the comparison of opinions with the local community. In this sense, the requirements of capillarity and steadfast adherence to the territory are fundamental elements as they guarantee the possibility of taking care of one's own living space and giving value to the initiative through constant monitoring in the territory (Fig. 2).

Through some scheduled meetings, was possible to provide an overall picture to reflect on the requisites necessary for the creation of open city to needs of inhabitants and, at a later date, to discuss some operational proposals on the themes of the laboratory. Starting from reflections and project scenarios proposed by the students and exposed to citizenship, some questions addressed aimed at understanding how the project can promote urban regeneration processes. This active collaboration has been fundamental to foster the planning process, in which citizens represent agents of change in the overall action of urban regeneration. These meetings triggered a process of progressive involvement

\footnotetext{
${ }^{9}$ The Department of Culture and Tourism of the Municipality of Sassari has been collaborating for some time with the LEAP research laboratory of the DADU to promote a debate on the territory concerning the urban perspectives of the city and to contribute to cultural, social, environmental and tourist development, through studies, research and cultural initiatives.

The neighbourhood committee for the historic centre of Sassari has established thanks to the will of a group of residents who felt the need to become active citizens to promote actions of physical and social recovery and promote the livability of the living space.

The associations involved in various stages in the process are the Intergremio Città di Sassari and theatre en vol.

The intergremio is an organization made up of the Gremi, which operate in the civil, religious, cultural and economic spheres and coordinate the activities and projects related to the Festa dei Candelieri di Sassari, since 2013 an intangible heritage of the humanity in the National Network of Grandi Macchine a Spalla.

The theatre en vol cooperative has been operating for over twenty years in the artistic field, considering the street as a place of research and representation. The group investigates, in particular, the transformation of the public space and, by involving the spectator/citizen through performances, the street becomes a place of action, meeting and comparison. Among the various activities, in particular Girovagando, an international street art festival that has been taking place regularly for twenty years in September, animating the streets and public spaces of the city. https://www.theatrenvol.org/it/.
} 


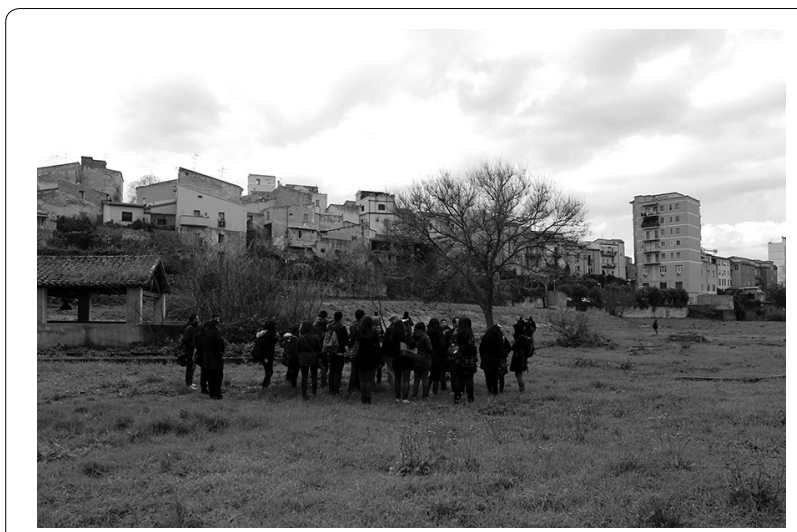

Fig. 2 Site visit to the project areas. Rosello Valley, Sassari. Photo: R. Filippelli

of apparently latent energies, but with a strong urban potential for the construction of cooperative networks. In this sense, participation, a potentially valuable tool for improving urban transformations, is a process not established a priori through phases and procedures, however, a complementary activity to the development of the project in its various phases to challenge it regularly. In this sense the project constitutes a "probe" to explore the possibilities of the reality that gives rise to positive or negative aspects producing an incremental knowledge: the process activated inside the laboratory has indeed triggered a response to contingencies, interacting with them, with the goal to promote urban regeneration of the historic city of Sassari.

The operative effectiveness of the spaces of comparison and discussion put in place during the various laboratory activities has declined through two different levels (Bateson 1977). The proto-learning, which concerns specific themes and contents, has carried out through a comparison with the specific questions that have discussed during the numerous meetings with institutions, committees and cultural associations operating in the area. The deutero-learning, that is the ability to "learn to learn" that does not concern the single phenomenon but the general context in which the activities took place, gave rise to an incremental knowledge and highlighted the repertoire of the possibility of reality (Fig. 3).

Through drawings, plastic models, photos, videos, etc., tools proper to the representation of the project, some hypotheses of reorganization of the urban space were illustrated in significant areas of the historical city with the aim of favoring the interaction between the different communities and in a vision attentive to the qualitative differences of places and subjects. The activities of the laboratories of the 2015-2016 and 2016-2017 academic years were accompanied by some significant moments of

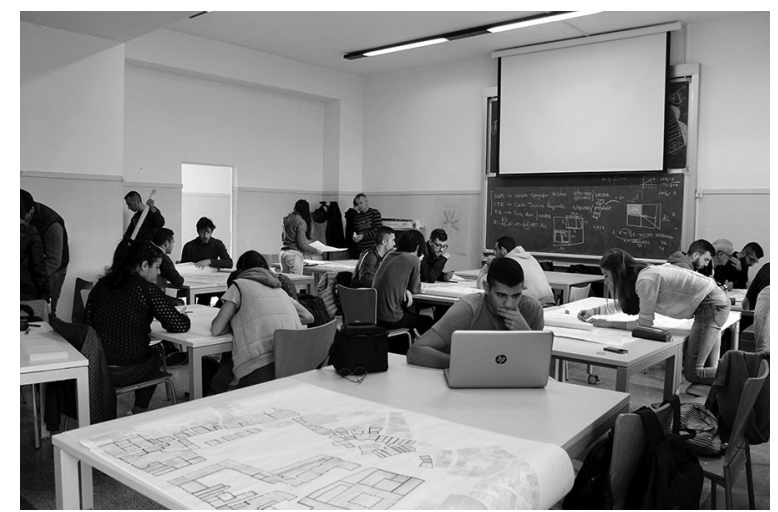

Fig. 3 Laboratory activities. Photo: R. Filippelli

reflection. In particular, during the months of June-July 2016, the exhibition Idee per una città accogliente. Laboratorio Città e Territorio, primo anno corsi di Architettura e Urbanistica ${ }^{10}$ was held in Sassari, at the exhibition site of the Museum of the City-Palazzo della Frumentaria. City and Territory Laboratory, first-year courses in Architecture and Urbanism that presented the projects developed by students in the educational laboratory. These hypotheses and project proposals offered relevant reflections for a useful contribution to the public debate on this part of the city (Fig. 4).

During the exhibition event of the projects took place some initiatives seminars and workshops in collaboration with institutions, committees and cultural associations operating in the territory. In particular, the workshopgame carried out with the children of the neighbourhood inspired by the experiences of Bruno Munari (1977) during which, using the imagination as a method to "learn to learn", invited the little ones to hypothesized relationships between some urban elements. Through these "creative errors" and "imperfect materials" the children were asked to verify and implement unexpected experiments, finding out what can be achieved by assembling things, rather than being guided towards a product to be made. This cultivated industriousness allowed the child to develop a creative planning thought, an attitude to see things differently from childhood. The laboratory, through a temporary space for meeting, training and collaboration, has given rise to a place of creativity,

\footnotetext{
10 The initiative, organized by the LEAP research laboratory and sponsored by the Department of Culture and Tourism of the Municipality of Sassari, presented the projects of the first year students of the Degree Courses in Sciences of Science from 24 June to 8 July 2016 Architecture and Project and in Urban Planning, Planning of the City, Territory, Environment and Landscape, developed during the City and Territory educational block, during the academic year 2015-2016.
} 


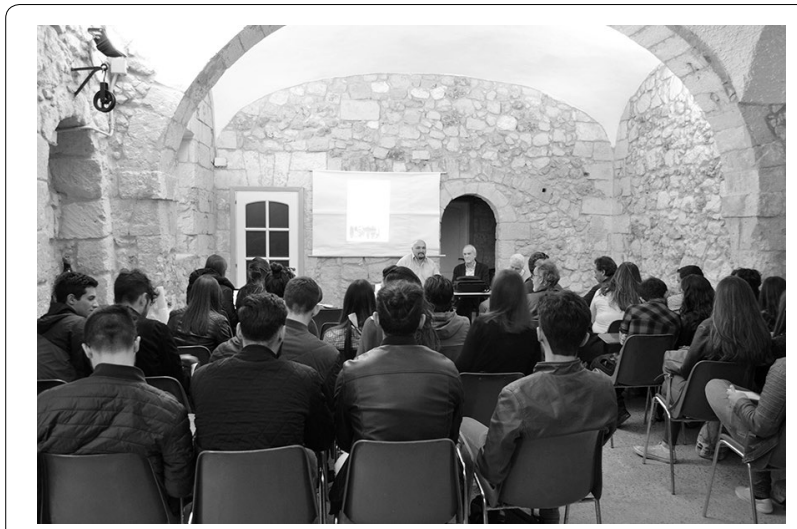

Fig. 4 Meeting with citizenship. Photo: R. Filippelli

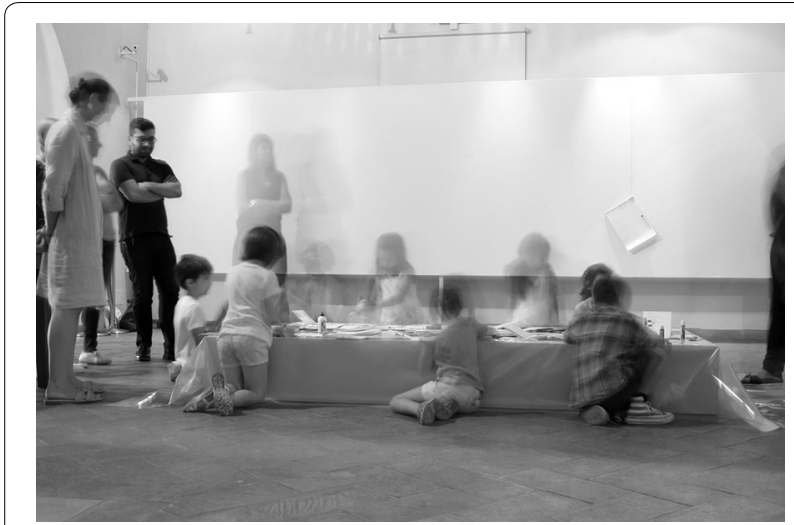

Fig. 5 Laboratory game by the research laboratory LEAP (S. Bartocci, G.M. Biddau, L. Lutzoni, M. Valentino). Palazzo della Frumentaria, Sassari, 2016. Photo: G.M. Biddau

experimentation, discovery and self-learning through play, an area in which to build knowledge (Fig. 5).

The exhibition ended with the seminar Reflections and operational proposals for the city of Sassari. Retracing the work done by the students, focused on the study of design solutions for essential areas of the historic city, was an opportunity to offer the inhabitants a moment of reflection on the possible scenarios of urban regeneration. The proposals that emerged during the debate constituted an interesting contribution to the "collective" construction process of this project that is associated with essential transformation processes (Fig. 6).

Also, during the study seminars and meetings with citizenship that accompanied the planning process of the second year of activity, the students illustrated the reorganization proposals of some areas of the city. The intent of the spatial recovery of places has been associated with the construction of constant exchange with the community to arrive at a process of urban regeneration that considers the city as a relationship space (Maciocco and

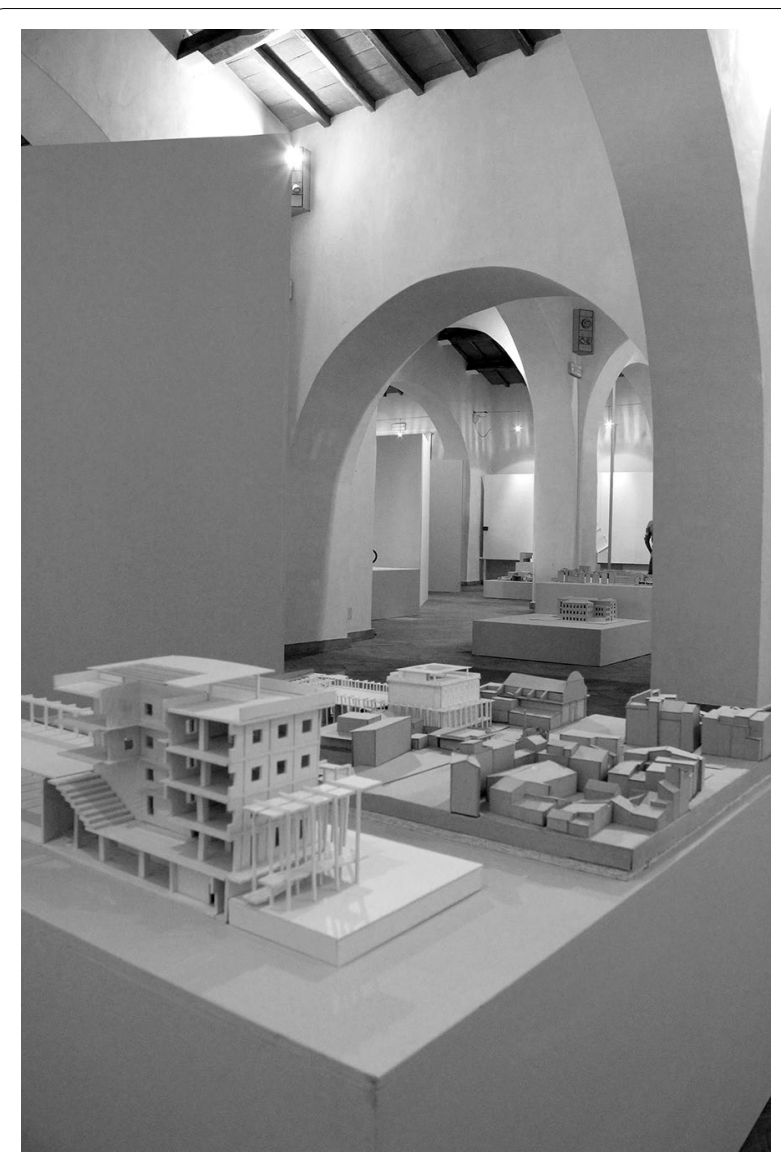

Fig. 6 Exhibition "Idee per una città accogliente", Palazzo della Frumentaria, 24 June - 8 July 2016, Sassari. Photo: G.M. Biddau

Tagliagambe 2009) in which many social dynamics manifested, spatial, cultural, economic, etc.

The structure and formation of the urban territory of Sassari constituted concerning a complex and articulated system of valleys, developed in the north-west direction. Observing the environmental structure of the territory, the close link between the city and its environmental system is evident, initially the driving force behind the settlement with its economies, and subsequently marginal space that not integrated into the urban life of the territory.

Starting of the need to activate a process of urban and environmental regeneration of the city of Sassari through study of relationship that becomes linked the city to the environmental system of the valleys in history, the activities of the laboratory concentrated on identifying all those latent traces of a system full of meaning and full of potential for urban life. In a reality like the contemporary one, dominated by the values of mobility, some places seem to express resistance: they are the dense places of nature and history with which the inhabitants continue 
to relate in a selective manner (Maciocco 2007). In this sense the environmental system can offer prospects for the territory, starting precisely from those marginal or abandoned areas (Maciocco and Pittaluga 2006; Maciocco et al. 2011b) that can represent an opportunity also to think about new relationship spaces and active participation.

In this perspective in which the city is increasingly territorial, even the traditional concept of public space appears inadequate to express the complexity of the current settlement systems. The alternative ways of reading the city-territory reveal a different order starting from elements considered marginal in the urban project in the past, such as the environmental system. The territory and its processes become part of the urban organization, offering the availability to think about different forms and ways of appropriation of the space. Starting from this urban-territorial conception, perspectives for public space emerge whose meaning is to found in the dynamics of social, economic and cultural reality in transformation, related to the specificities of places (Serreli 2013).

In this general framework, the project formed through the identification of a set of urban nuclei, spaces and significant areas of the city that create "tension". These localized elements have taken on a general meaning, recalling the structure-form of the city (De Carlo 2008): starting from these, an overall order has identified which finds its generative structure in the environmental system of the city valleys. These nuclei become the occasion to relate spaces of different nature, involving open and interstitial areas hidden within public buildings that are redesigned to become places of being. At the same time, secondary generative structures allow urban generative structures to be integrated with urban centres, giving rise to a nonhierarchical but relational urban landscape. In this way, the project becomes an opportunity for the more general design of the city, where a more democratic organization subverts the hierarchy of the parts. The environmental generative structures, recognized in the environmental specificity of the valleys (Maciocco et al. 2011b), are anchored to the secondary generative structures that, crossing transversally the historical city, relate the single fragments of project (Gregotti 2008) in the attempt to give a different meaning to the general starting from the particular.

The involvement of these areas in an urban regeneration project implies the inclusion of new ordering elements that introduced into the pre-existing urban fabric. In this perspective, new urban geographies are configured assuming environmental emergencies as references of an urban re-composition. The city can build an environmental perspective through the reorientation of the valleys (Maciocco et al. 2011b) which allow to bring some peripheral situations back to the centre through transformations of the historical fabric, to try to adapt it to the new urban needs.

Starting from the project proposals and the activities promoted within the laboratory, some reflections have started aimed at determining an urban perspective for the city of Sassari, assuming as a fundamental element the recognition of the propensity of urban contexts to change.

In the experience developed in the city of Sassari, we tried to understand how the city could be "inhabited" by education. The city has interpreted as an observable landscape concerning the experience of living. The planning tool of the urban core is part of the territory thanks to its ability to generate relationships at different spatial scales. These are contact spaces (Choay 2003), places where culture is transmitted, through a perspective that considers the city, in its many forms and dimensions, as a place of learning. Thus, a localized structure for the activities that leads to a reticular organization of the territory outlined. Education takes on this task, and through the design of diversified spaces (such as residence, spaces for interfacing with the city, meeting spaces, etc.) a process of educational "contamination" begins. This territorial plot of urban conviviality builds a mutual belonging between school and territory capable of bringing out a different organization.

This trend implies the need to experiment through the project of space if there are favourable conditions for places to become educational. The project is therefore defined not only about its ability to realize the spatial conditions predetermined in the designers' symbolic frameworks so that learning can take place. Associating the space project with education implies going beyond an individual and unilateral understanding of the phenomena of change in favour of a collectively produced knowledge, based on multiple social, cultural, economic relations, etc. This change in the concept of knowledge influences the project because to act it is not enough to interpret knowledge as a communication of knowledge. However, it becomes fundamental to explore the human condition by developing an attitude towards "knowledge of knowledge" (Morin 2015). In this perspective, the project assumes a significant value as a tool of knowledge to explore the conditions of reality. To change the character of models and techniques for the construction of knowledge in a non-procedural sense means to overcome the procedural linearity of the relationship between knowledge and action and to aim at new horizons that reward the relevance of design knowledge to analytical knowledge (Maciocco 2005, p. 16). In the constructivist perspective, the project defines itself as a driver of change, and in particular as the tool aimed at bringing out an 
unprecedented organization aimed at relating different elements and assigning each part a specific urban quality, identifying for each element of the plays a role in the general scenario. It is precisely relating that strengthens the individual elements. Furthermore, the transition from a socio-spatial perspective towards an understanding of the city as a relational sphere linked to learning processes implies as a consequence the need to distance oneself from an ontology traditionally modeled on the "thing", on closed entities and bearers of property that characterize them as such in a specific and exclusive way, to an ontology hinged, instead, on the concept of relationship (Tagliagambe 2008).

\section{Acknowledgements}

Not applicable.

\section{Authors' contributions}

This article is the result of joint research undertaken by the two authors. MV has written the first paragraph, LL the second paragraph, both authors the third paragraph. Both authors read and approved the final manuscript.

\section{Funding}

Not applicable.

\section{Availability of data and materials}

Not applicable.

\section{Ethics approval and consent to participate}

Not applicable.

\section{Consent for publication}

Not applicable.

\section{Competing interests}

We declare that we have no competing interests.

\section{Author details}

${ }^{1}$ Dipartimento Di Architettura, Design E Urbanistica, Università Degli Studi Di Sassari, Alghero, Italy. ${ }^{2}$ Ministero per i beni e le attività culturali e per il turismo - MiBACT Soprintendenza Archeologia, belle arti e Paesaggio Per Le Province Di Sassari E Nuoro, Sassari, Italy.

Received: 21 December 2019 Accepted: 6 March 2020 Published online: 18 March 2020

\section{References}

Bateson G (1977) Verso un'ecologia della mente. Adelphi Edizioni, Milano Bauman Z (2008) Individualmente insieme. Diabasis, Parma Bauman Z 2011, Modernità liquida. Laterza, Roma-Bari

Bauman Z (2014) La solitudine del cittadino globale. Feltrinelli, Milano

Brusa A (2012) Dalla città come aula alla città-archivio. Note per un possibile curricolo verticale sulla città. Available via DIALOG. archivio.comune.pv.ti/ museicivici/pdf/annali28/49\%20Brusa\%20Didattica.pdf. Accessed 21 June 2019.

Cacciari M (2004) La città. Pazzini Editore, Villa Verucchio

Campagnoli G (2007) L'architettura della scuola. Un'idea per i luoghi della cultura e dell'apprendere, FrancoAngeli, Milano

Campagnoli G (2015) Oltre le aule. La scuola en plein air, ReseArt Productions, Pesaro

Castells M (1977) The urban question: a marxist approach. The MIT Press, Cambridge

Choay F (2003) Espacements. Figure di spazi urbani nel tempo, Skira, Milano Clemente F (ed) (1969) Università e territorio. La Nuova Italia, Bologna
Clemente F (ed) (1974) I contenuti formativi della città ambientale. Pacini, Pisa Corboz A (1985) II territorio come palinsesto Casabella 516:22-27

De Carlo G (1947) La scuola e l'urbanistica. Domus 220:15-17

De Carlo G (1972) Ordine-istituzione educazione-disordine Casabella 368-369:65-71

De Carlo G (2008) Questioni di architettura e urbanistica. Maggioli Editore, Rimini

De Solà-Morales I (1995) Terrain Vague. In: Davidson C (ed) Anyplace. The MIT Press, Cambridge

Foucault M (2007) Sicurezza, territorio, popolazione. Feltrinelli, Milano Gabellini P (1996) II disegno urbanistico. Nuova Italia Scientifica, Roma Gallo L, Mottana P (2017) Educazione diffusa. Per salvare il mondo e i bambini, Dissensi, Viareggio

Gottmann J (2005) II significato del territorio. Nexta, Roma

Goodman P (1964) Compulsory miseducation. Horizon Press, New York Gregotti V (2008) II territorio dell'architettura. Feltrinelli, Milano

Illich I (1972) Descolarizzare la società. Mondadori, Milano

Indovina F (2005) La nuova dimensione urbana. L'arcipelago metropolitano. In: Marcelloni M (ed) Questioni della città contemporanea. FrancoAngeli, Milano.

Jenks C (2005) The iconic building. The power of enigma, Frances Lincoln, London

Lefebvre H (1977) Critica della vita quotidiana. Dedalo, Bari

Lo Piccolo F (2017) Nuovi confini e limiti delle città. Urbanistica Informazioni 272:3-4

Lyotard JF (2008) La condizione postmoderna. Rapporto sul sapere, Feltrinelli, Milano

Lutzoni L (2017) Trame di apprendimento e innovazione sociale. In: Serreli S, Calidoni P, Città e formazione. Esperienze fra urbanistica e didattica. FrancoAngeli, Milano.

Maciocco G (ed) (1991) Le dimensioni ambientali della pianificazione urbana. FrancoAngeli, Milano

Maciocco G (2005) Modelli, tecniche e poetiche del computer. In: Cecchini A, Plaisant A (eds) Analisi e modelli per la pianificazione. Teoria e pratica: lo stato dell'arte. FrancoAngeli, Milano.

Maciocco G. 2007, Architecture, environment and beyond. Skira, Milano.

Maciocco G, Sanna G, Serreli S (eds) (2011a) The urban potential of external territories. FrancoAngeli, Milano

Maciocco G, Balestrieri M, Congiu T (eds) (201 1b) II progetto urbano del territorio. Il piano strategico della provincia di Sassari, FrancoAngeli, Milano

Maciocco G, Lutzoni L, Valentino M (eds) (2018) Strutture generative e nuclei di urbanità. FrancoAngeli, Milano

Maciocco G, Pittaluga P (eds) (2006) II progetto ambientale in aree di bordo. FrancoAngeli, Milano

Maciocco G, Tagliagambe S (1997) La città possibile: territorialità e comunicazione nel progetto urbano. Edizioni Dedalo, Bari

Maciocco G, Tagliagambe S (2009) People and space. New forms of interaction in city project. Springer Verlag, Heidelberg, Berlin, New York.

Marcelloni M (ed) (2005) Questioni della città contemporanea. FrancoAngeli, Milano

McLuhan M, Hut K, McLuhan E (1980) Città come aula. Per capire il linguaggio e i media, Armando Editore, Roma

Mela A (2018) Bauman e la città: da 'deserto sovraffollato'a luogo civile. In: LABSUS - Laboratorio per la Sussidiarietà. Available via DIALOG. https:// www.labsus.org/2018/02/bauman-la-citta-deserto-sovraffollato-luogo -civile. Accessed 15 Mar 2018.

Merrifield A (2014) The new urban question. Pluto Press, London

Michelucci G (2010) La scuola e la città. In: Checchi P, Marcetti C, Maringolo P (a cura di) La scuola e la città. Polistampa, Firenze, pp 13-18

Morin E (2015) Insegnare a vivere. Manifesto per cambiare l'educazione, Raffaello Cortina Editore, Milano

Mottana P, Campagnoli G (2016) La città educante. Manifesto della educazione diffusa. Come oltrepassare la scuola, Asterios Editore, Trieste

Mumford L (1999) La cultura della città. Edizioni di Comunità, Milano

Munari B (1977) Fantasia. Universale Laterza, Bari

Ostanel E (2017) Spazi fuori dal comune: rigenerare, includere, innovare. FrancoAngeli, Milano

Reimer E (1973) La scuola è morta. Armando Editore, Roma

Rogers EN (1947) Architettura educatrice. Domus 220:1

Rossi A (1966) L'architettura della città. Marsilio, Padova

Secchi B (1986) Progetto di suolo Casabella 520:19-23 
Secchi B (2000) Prima lezione di urbanistica. Laterza, Roma-Bari Secchi B (2010) A new urban question Territorio 53:8-18

Sernini M (2000) I processi metropolitani: scenari Controspazio 2:6-14

Serreli S (ed) (2013) City project and public space. Springer Verlag, Heidelberg, Berlin, New York

Serreli S, Calidoni P (2017) Città e formazione. Esperienze fra urbanistica e didattica, FrancoAngeli, Milano

Tagliagambe S (2005) Le due vie della percezione e l'epistemologia del progetto. FrancoAngeli, Milano

Tagliagambe S (2008) Lo spazio intermedio. Università Bocconi Editore, Milano Ward C (1973) Schools no longer. In: Ward C, Anarchy in action. Allen \& Unwin and Freedom Press, London.
Ward C (2000) II bambino e la città. Crescere in ambiente urbano. L'ancora del Mediterraneo, Napoli

Ward C, Fyson A (1973) Streetwork: the exploding school. Routledge, London

\section{Publisher's Note}

Springer Nature remains neutral with regard to jurisdictional claims in published maps and institutional affiliations.

\section{Submit your manuscript to a SpringerOpen ${ }^{\circ}$ journal and benefit from:}

- Convenient online submission

- Rigorous peer review

- Open access: articles freely available online

- High visibility within the field

- Retaining the copyright to your article

Submit your next manuscript at $\mathbf{s p r i n g e r o p e n . c o m ~}$ 